\title{
Effect of Oral N-Acetylcystein on Galectin-3 in Acute Myocardial Infarction Patients
}

\author{
Akhmad Jalaludinsyah ${ }^{1,2)}$, Trisulo Wasyanto, ${ }^{1,2)}$, Niniek Purwaningtyas ${ }^{1,2)}$ \\ 1)Department of Cardiology and Vascular Medicine, \\ Faculty of Medicine, Universitas Sebelas Maret \\ 2)Dr. Moewardi Hospital, Surakarta
}

\begin{abstract}
Background: The pathogenesis of heart failure after myocardial infarction is associated with the pathogenesis of cardiac remodeling. Galectin-3 (Gal-3) has a role in the pathophysiology of cardiac remodeling after acute myocardial infarction. N-Acetylcysteine (NAC) can prevent inflammation, remodeling and left ventricular dysfunction, interstitial fibrosis, and improve survival. The purpose of this study was to examine effect of oral N-Acetylcystein on Galectin-3 in acute myocardial infarction patients.

Subjects and Method : This was an experimental study with pre and post, single blind, and randomization methods. The study was conducted at Dr.Moewardi General Hospital Surakarta, Central Java, from June to August 2018. A sample of 29 acute myocardial infarction patients with ST segment elevation who received fibrinolytic therapy was selected for this study. 14 patients as a control group received standard therapy and 15 patients as intervention group received oral NAC supplementary therapy $600 \mathrm{mg}$ three times daily for three days. The dependent variable was Gal-3 levels. The independent variable was NAC supplementary therapy.The data were analyzed by Mann Whitney test.

Results : Gal-3 levels in intervention group (mean=8.95; $\mathrm{SD}=1.76)$ were lowered than the control group (mean=11.42; $\mathrm{SD}=3.76)$ and it was statistically significant $(\mathrm{p}=0.026)$.

Conclusion : Supplementary therapy of NAC $600 \mathrm{mg}$ orally 3 times a day for 3 days can reduce levels of Gal-3 in patients with acute myocardial infarction who receive fibrinolytic therapy.
\end{abstract}

Keywords : galectin-3, n-acetylcysteine, acute myocardial infarction

\section{Correspondence:}

Akhmad Jalaludinsyah. Department of Cardiology and Vascular Medicine, Faculty of Medicine, Universitas Sebelas Maret. Universitas Sebelas Maret, Jl. Ir. Sutami 36A, Surakarta 57126, Central Java, Indonesia. Email: dokter.akhmad@gmail.com. Mobile: +6281393098987.

\section{BACKGROUND}

Coronary heart disease is the leading cause of death worldwide (Hartley et al., 2016). Death from cardiovascular disease in Indonesia is increasing every year and cardiovascular disease is the most common cause of death (Dharma et al., 2012). More than three million people are estimated to suffer from IMA EST and more than four million people suffer from non-EST IMA. Previously IMA was more common in developed countries, but currently the incidence of IMA is increasing in developing countries
(White and Chew, 2008). Data obtained from Jakarta Acute Coronary Syndrome (JAC) Registry from 2008-2009 were obtained in 2013 patients with acute coronary syndrome, of which 654 patients suffered IMA EST and 622 patients suffered non-EST IMA treated at the Harapan Kita National Heart Center (Dharma et al. , 2012).

In a study in patients with IMA, there was a decrease in 5-year mortality rates (from $41.1 \%$ in the 1970 s to $17.3 \%$ in the 1990s) associated with a significant incre- 
ase in the incidence of heart failure in 5 years (from $27.6 \%$ in the 1970 s to $31.9 \%$ in the 1990s) (Velagaleti et al., 2008). The pathogenesis of heart failure after myocardial infarction is associated with the pathogenesis of cardiac remodeling, a constellation of geometric, morphological, molecular and functional changes involving or not myocardial infarction, causing space dilatetion and ventricular dysfunction, and associated with poor outcome. The severity of post-infarction myocardial remodeling depends, not only on infarct size, but also on the qualitative characteristics of the reparative response (Pfeffer and Braunwald, 1990).

N-Acetylcysteine (NAC) can prevent inflammation, left ventricular remodeling and dysfunction, interstitial fibrosis, and improve survival in animal studies (Waard et al., 2009). In patients with fibrinolytic IMA EST, administration of NAC can reduce the levels of matrix metalloproteinase (MMP) -9 and 2 which play a role in post-infarct heart remodeling while reducing major adverse cardiac events (MACE) in meaningful one-year follow-up (Talasaz et al., 2014). Reduction in infarction size also occurred significantly with the administration of NAC in IMA EST patients who performed percutaneous coronary intervention (IKP) primers (Pasupathy et al., 2017).

Remodeling after myocardial infarction is caused by acute loss of myocardium, which causes structural and biomechanical changes in an effort to maintain cardiac function. Formation of fibrous tissue is important in this case, including in the initial phase and further conditions after the IMA. Galectin-3 (Gal-3), a lectin that binds to $\beta$-galactoside, has a major role in the development of heart fibrosis under conditions of excessive pressure (pressure overload), neuro-endocrine activation, and hypertension, but its role in remodeling after IMA has not gotten enough attention. However, in various studies in rats, it showed Gal-3 expression in the myocardium after increased myocardial infarction, both at the level of mRNA and protein, during the initial phase in the infarct and surrounding areas, and also in the advanced phase which contributed to tissue repair and fibrosis (Meijer et al., 2015; Sharma et al., 2016).

Van der Velde et al. (2016), 247 IMA EST patients who underwent primary IKP, Gal-3, as biomarkers of fibrosis, who were taken after IMA could predict left ventricular ejection fraction and infarct area after 4 months. Therefore from this study it is concluded that Gal-3 has a role in the pathophysiology of cardiac remodeling after IMA. Genetic disruption and pharmacological inhibition of Gal-3 can reduce heart fibrosis, left ventricular dysfunction and the development of heart failure, giving rise to the impression that administration of drugs related to Gal-3 inhibition can be potential therapeutic candidates to prevent or improve the incidence of heart failure with extensive fibrosis ( $\mathrm{Yu}, 2012)$. To the knowledge of the researchers, until now there has been no research on the effect of additional oral N-Acetylcystein therapy on Gal-3 levels in patients with IMA receiving fibrinolytic therapy.

\section{SUBJECTS AND METHOD \\ 1. Study Design \\ This was a randomized controlled trial carried out at Dr. Moewardi Hospital, Sura- karta, Central Java, from June to August 2018.}

\section{Study Subjects}

A sample of 29 acute myocardial infarction patients with ST segment elevation who received fibrinolytic therapy was selected for this study by concecutive sampling. 
Samples were taken consecutively in patients with IMA EST who received fibrinolytic therapy who were treated at ICVCU and were willing to take blood for this study.

Inclusion criteria, namely patients with IMT EST with symptom onset of less than 12 hours and fibrinolytic action, patients aged 18-75 years, and no absolute contraindications to the action of fibrinolysis. As for exclusion criteria, namely patients with a history of previous SKA or chronic heart failure, patients with valvular heart disease, patients with chronic renal failure, patients with hepatic cirrhosis, patients with chronic inflammatory disease or malignancies, patients with acute infection or sepsis, and patients with acute stroke.

\section{Study Variables}

Acute myocardial infarction with ST segment elevation was defined by clinical syndrome with typical symptoms of chest pain as a symptom of myocardial ischemia associated with ECG images in the form of ST segment elevation calculated from point $\mathrm{J}$ in at least 2 adjacent leads $\geq 2 \mathrm{~mm}(0.2 \mathrm{mV})$ in men or $\geq 1.5 \mathrm{~mm}(0.15 \mathrm{mV})$ in women in leads $\mathrm{V}_{2}-\mathrm{V}_{3}$ and or $\geq 1 \mathrm{~mm}(0.1 \mathrm{mV})$ in other leads in the chest or limb leads and release of biomarkers of myocardial necrosis (Ibanez et al., 2017).

Fibrinolytic was indicated in IMA patients with ST segment elevation and patients coming to hospital within 12 hours after symptoms are first felt. In this study fibrinolytics used a 1.5 million unit Streptokinase preparation diluted in $100 \mathrm{cc} \mathrm{NaCl}$ and inserted intravenously for 30-60 minutes (Ibanez et al., 2013).

$\mathrm{N}$-Acetylcysteine used was a $600 \mathrm{mg}$ effervescent tablet (Fuimucil@, Zambon Switzerlan Ltd) with treatment given $3 \times 600$ mg for 3 days. Gal-3 levels were measured using Human Galectin-3 Quantikine ELISA (R \& D System, USA).

\section{Data analysis}

Data presented in the form of a mean and standard deviation were then analyzed between treatment and control groups before and after treatment. The data were analyzed by Mann Whitney test.

\section{Research Ethics}

Research ethics including informed consent, confidentiality, and ethical clearance was obtained from Dr. Moewardi hospital, Surakarta, Central Java.

\footnotetext{
RESULTS

A total of 29 patients were included in this study: 14 control group patients who received standard therapy and 15 group patients who received oral NAC supplementary therapy $600 \mathrm{mg}$ three times a day for three days. The results of testing the homogeneity of the subject's basic characteristic variables, both qualitative and quantitative, found that all basic characteristic variables were homogeneous because the mean differences in the characteristic variables in the two groups namely the NAC group and the control group were not significant at the 5\% significance level 0.05).

The results of different tests 2 the mean NAC group and control group for the Gal-3 variable in the condition after administration of therapy showed significant test results $(\mathrm{p}=0.026)$. Thus the variable levels of Gal-3 for NAC and the control group in conditions after administration of therapy differed significantly or not the same. This can be interpreted that after getting standard therapy plus NAC in the NAC group and standard therapy alone in the control group, there was a significant difference in the variable Gal-3 level, because the NAC group changed while the control group tended to remain.
} 
Table 1. Univariate analysis

\begin{tabular}{|c|c|c|c|c|c|c|}
\hline \multirow{2}{*}{ Independent Variable } & \multicolumn{2}{|c|}{ Control Group } & \multicolumn{2}{|c|}{ NAC Group } & \multicolumn{2}{|c|}{ Chi Square Test } \\
\hline & $\mathrm{n}$ & $\%$ & $\mathrm{n}$ & $\%$ & OR & $\mathrm{p}$ \\
\hline \multicolumn{7}{|l|}{ Geder } \\
\hline a. Male & 12 & 85.7 & 14 & 93.3 & \multirow[b]{2}{*}{0.453} & \multirow[b]{2}{*}{0.501} \\
\hline b. Female & 2 & 14.3 & 1 & 6.7 & & \\
\hline \multicolumn{7}{|c|}{ Type of Location of IMA EST } \\
\hline a. Anterior & 8 & 57.1 & 10 & 66.7 & \multirow{2}{*}{0.279} & \multirow{2}{*}{0.597} \\
\hline b. Non-Anterior & 6 & 42.9 & 5 & 33.3 & & \\
\hline \multicolumn{7}{|l|}{ Killip class } \\
\hline a. 1 & 10 & 71.4 & 11 & 73.3 & \multirow{3}{*}{0.013} & \multirow{3}{*}{0.909} \\
\hline b. $2-4$ & 4 & 28.6 & 4 & 26.7 & & \\
\hline \multicolumn{5}{|l|}{ Hypertension Status } & & \\
\hline a. Yes & 9 & 64.3 & 10 & 65.5 & \multirow{3}{*}{0.018} & \multirow{3}{*}{0.893} \\
\hline b. No & 5 & $35 \cdot 7$ & 5 & 34.5 & & \\
\hline \multicolumn{5}{|l|}{ Smoking Status } & & \\
\hline a. Yes & 9 & 64.3 & 11 & $73 \cdot 3$ & \multirow{3}{*}{0.277} & \multirow{2}{*}{0.599} \\
\hline b. No & 5 & $35 \cdot 7$ & 4 & 26.7 & & \\
\hline \multicolumn{6}{|l|}{ Status Diabetes mellitus } & \\
\hline a. Yes & 1 & 7.1 & 4 & 26.7 & \multirow{3}{*}{3.137} & \multirow{3}{*}{0.077} \\
\hline b. No & 13 & 92.9 & 11 & $73 \cdot 3$ & & \\
\hline \multicolumn{5}{|c|}{ Status of Fibrinolytic Success } & & \\
\hline a. Succeed & 3 & 21.4 & 2 & $13 \cdot 3$ & \multirow{2}{*}{0.333} & \multirow{2}{*}{0.564} \\
\hline b. Failed & 11 & 78.6 & 13 & 86.7 & & \\
\hline
\end{tabular}

Table 2. Sample Characteristics

\begin{tabular}{lcccccc}
\hline \multirow{2}{*}{ Variable } & \multicolumn{2}{c}{ Control Group } & \multicolumn{2}{c}{ NAC Group } & \multicolumn{2}{c}{ 2Average Difference Test } \\
\cline { 2 - 7 } & Mean & SD & Mean & SD & Statistical Value & p \\
\hline Age & 58.21 & 8.37 & 56.40 & 10.27 & $\mathrm{t}=0.519$ & 0.609 \\
Onset & 4.96 & 2.67 & 4.93 & 2.68 & $\mathrm{t}=0.031$ & 0.975 \\
SBP & 132.36 & 28.41 & 137.73 & 24.88 & $\mathrm{t}=-0.543$ & 0.592 \\
DBP & 81.07 & 19.38 & 83.73 & 17.05 & $\mathrm{t}=-0.393$ & 0.697 \\
HR & 77.71 & 12.33 & 74.80 & 20.20 & $\mathrm{t}=0.465$ & 0.646 \\
TIMI Score & 4.64 & 2.34 & 3.53 & 1.30 & $\mathrm{Z}=-1.072$ & 0.310 \\
Hb & 13.59 & 1.88 & 13.63 & 1.72 & $\mathrm{t}=-0.071$ & 0.944 \\
HT & 41.43 & 5.67 & 41.27 & 4.37 & $\mathrm{t}=0.087$ & 0.932 \\
Leukocytes & 10.90 & 3.73 & 11.73 & 4.11 & $\mathrm{t}=-0.571$ & 0.573 \\
Thrombocytes & 247.04 & 87.78 & 265.17 & 62.51 & $\mathrm{t}=-0.644$ & 0.525 \\
Erythrocytes & 4.78 & 0.62 & 4.73 & 0.57 & $\mathrm{t}=0.218$ & 0.829 \\
eGFR & 73.87 & 30.30 & 63.92 & 25.61 & $\mathrm{t}=0.957$ & 0.347 \\
Hs-Trop I & 1907.56 & 1839.14 & 2107.65 & 2815.91 & $\mathrm{Z}=-0.393$ & 0.715 \\
Blood sugar & 136.71 & 32.40 & 156.47 & 65.69 & $\mathrm{t}=-1.015$ & 0.319 \\
LDL & 141.29 & 85.08 & 130.20 & 30.28 & $\mathrm{Z}=-0.284$ & 0.780 \\
LVEF & 44.21 & 8.22 & 44.60 & 11.61 & $\mathrm{t}=-0.103$ & 0.919 \\
\hline
\end{tabular}

$\mathrm{SBP}=$ systolic blood pressure, $\mathrm{DBP}=$ diastolic blood pressure, $\mathrm{HR}=$ heart rate, TIMI $=$ Thrombolysis in Myocardial Infarction, $\mathrm{Hb}=$ hemoglobin, HT = hematocrit, eGFR = estimated glomerular filtration rate, HsTrop I = high sensitive troponin $\mathrm{I}, \mathrm{LDL}=$ low-density lipoprotein, $\mathrm{LVEF}=$ left ventricle ejection fraction

The results of different test 2 mean of the variable Gal-3 levels before and after therapy in the NAC group produced a significant difference $(\mathrm{p}=0.001)$. However, the mean difference testing of the Gal-3 level variables before and after administration of therapy in the control group produced a non-significant difference $(\mathrm{p}=$ 
0.344). This means that in the NAC group, giving standard therapy plus NAC can significantly reduce the Gal-3 level variable, but in the control group it cannot signifycantly reduce the Gal-3 variable.

Variable changes in Gal-3 levels in the NAC group and the control group both have data that are normally distributed, so different testing 2 mean changes in Gal-3 levels in the NAC group and the control group can use different test 2 mean $t$ test for independent samples. The results of the calculation of the difference test 2 mean with the $t$ test for the independent sample between the variable changes in Gal-3 levels in the NAC group and the control group showed that the variable changes in Gal-3 levels differed significantly $(\mathrm{p}=$ o.006). This condition shows that giving standard therapy plus NAC in the NAC group can actually reduce Gal-3 levels significantly.

Table 3. Comparison of Gal-3 levels on NAC and control groups before and after treatment

\begin{tabular}{lcccccc}
\hline \multirow{2}{*}{ Variable } & \multicolumn{2}{c}{ Control Group } & \multicolumn{2}{c}{ NAC Group } & \multicolumn{2}{c}{ 2 Average Difference Test } \\
\cline { 2 - 7 } & Mean & SD & Mean & SD & Statistical Value & p \\
\hline Before & 12.91 & 4.02 & 15.99 & 4.77 & $\mathrm{t}=-1.88$ & 0.072 \\
After & 11.42 & 3.76 & 8.95 & 1.76 & $\mathrm{Z}=-2.23$ & 0.026 \\
\hline
\end{tabular}

Table 4. Comparison of Gal-3 levels before and after therapy NAC and control groups

\begin{tabular}{lcccccc}
\hline \multirow{2}{*}{ Variable } & \multicolumn{2}{c}{ Before } & \multicolumn{2}{c}{ After } & \multicolumn{2}{c}{ Test t of 2 average difference } \\
\cline { 2 - 7 } & Mean & SD & Mean & SD & Statistical Value & p \\
\hline Control Group & 12.81 & 4.02 & 11.42 & 3.76 & $\mathrm{t}=0.98$ & 0.344 \\
NAC Group & 15.99 & 4.77 & 8.95 & 1.76 & $\mathrm{t}=6.31$ & 0.001 \\
\hline
\end{tabular}

Table 5. Comparison of changes in (delta) Gal-3 levels in the NAC and control groups

\begin{tabular}{ccccccc}
\hline \multirow{2}{*}{ Variable } & \multicolumn{2}{c}{ Control Group } & \multicolumn{2}{c}{ NAC Group } & \multicolumn{2}{c}{ 2 Average Difference Test } \\
\cline { 2 - 7 } & Mean & SD & Mean & SD & Statistical Value & p \\
\hline $\begin{array}{c}\text { Changes in } \\
\text { Gal-3 levels }\end{array}$ & -1.50 & 5.70 & -7.04 & 4.33 & $t=2.97$ & 0.006 \\
\hline
\end{tabular}

\section{DISCUSSION}

Remodeling after myocardial infarction is caused by acute loss of myocardium, which causes structural and biomechanical changes in an effort to maintain cardiac function. Formation of fibrous tissue is important in this regard, including in the initial phase and further conditions after IMA (Meijer et al., 2015; Sharma et al., 2016).

Galectin-3 is secreted by macrophages which are activated and modulate several physiological and pathological processes, including inflammation and fibrosis. Galectin-3 directly induces fibroblasts to proliferate and deposit type I collagen in the extracellular matrix (Yang et al, 2008; Sharma et al, 2016). In the study by van der Velde et al. (2016) with 247 patients with IMA EST who underwent primary IKP, Gal3 , as a biomarker of fibrosis, taken after IMA can predict left ventricular ejection fraction and infarct area after 4 months. Another study by Tano et al (2017) involved 103 patients with Anterior ESA who had occlusion in the left anterior descending 
artery (LAD) who underwent primary IKP then followed for 6 months, remodeling occurred in patients with higher Gal-3 at the time baseline, 1 month and 6 months.

The findings of this study showed that there were significant differences in Gal-3 levels between the control group and the treatment group after administration of NAC 600 mg orally 3 times a day for 3 days, there were also significant differences in Gal-3 levels in the treatment group before and after treatment where this significant difference was not found in the control group. In addition to that, there was a significant decrease (delta Gal-3) between the control and treatment groups. Therefore, the administration of NAC in this study can significantly reduce Gal-3 levels in IMA patients receiving fibrinolytic therapy. The results of this study are in line with the research conducted by Talasaz et al. in 2014 aimed at evaluating the effect of NAC on cardiac remodeling by using MMP-9 and MMP-2 levels in 98 IMA patients. In the group of patients who received oral NAC supplementary therapy, MMP-9 and MMP2 levels were significantly lower than the placebo group $(\mathrm{p}=0.014$ and $\mathrm{p}=0.045$, respectively). In the previous year, Talasaz et al. (2013) conducted a study to determine the effect of NAC on pro-fibrotic cytokines, TGF- $\beta$, and inflammation, TNF- $\alpha$, in IMA patients. In this study it was concluded that administration of NAC can prevent TGF- $\beta$ increases compared to those not given and TGF- $\beta$ has a strong association with left ventricular ejection fraction, therefore its antagonism may be important in preventing remodeling.

Decreasing Gal-3 levels through NAC administration can be explained by an indirect inhibiting mechanism through its role as an antioxidant and anti-inflammatory. Production of ROS due to myocardial ischemia activates inflammatory signals in myocardial infarcts. Reactive oxygen species increases leukocyte infiltration into existing infarcts in the healing process by activating all steps of inflammatory cell recruitment (Fan et al., 2001; Christia and Frangogiannis, 2013). N-Acetylcysteine is a ROS scavenger as a direct antioxidant, but its main role as a therapeutic antioxidant comes from its role as a precursor of cysteine in the synthesis of GSH. Under conditions of oxidative stress, the amount of GSH is reduced and this can be returned by NAC supplementation (Atkuri et al., 2007). Induction of pro-inflammatory transcription factors activator protein-1 (AP-1) and nuclear factor- $\mathrm{kB}(\mathrm{NF}-\mathrm{\kappa B})$ is inhibited by NAC. These transcription factors are induced in response to oxidative stress thus supporting the argument that the antiinflammatory properties of NAC are due to its mechanism of action as an antioxidant (Pinkus et al., 1996; Radomska and Skopiñski, 2012).

Transforming growth factor- $\beta$ is an important mediator in the remodeling process (Talasaz et al., 2011). Differentiation and activation of fibroblasts into myofibroblast by inflammatory cytokines, such as TGF- $\beta$, preceded by the entry of cells such as macrophages is the first step in the process of fibrogenesis. Galectin-3 plays a role in this process where macrophages and TGF- $\beta$ induce activation of myofibroblast through Gal-3, but recruitment of macrophages and expression of TGF- $\beta$ does not depend on Gal-3 (Yu, 2012).

Ischemia that occurs after IMA will trigger an increase in levels of pro-fibrotic cytokines, TGF- $\beta$, which induce fibrotic deposition in cardiomyocytes. Transforming growth factor- $\beta$ plays a significant role in the pathogenesis of the remodeling process, because inhibitory activity on TGF- $\beta$ in the proliferative phase of remodeling can prevent left ventricular hypertrophy and 
reduce the expansion of fibrosis in segments of the myocardium that do not experience infarction, and improve geometry left ventricle. N-Acetylcysteine can convert this cytokine into its inactive form and inhibit the binding of these cytokines to its receptors. On the other hand, fibronectin, a glycoprotein involved in tissue remodeling, can be released in response to various cytokines that include TGF- $\beta$ as the strongest stimulator. Thus, through inhibition of fibronectin production induced by TGF- $\beta$, NAC can be effective in blocking tissue remodeling (Sugiura et al., 2009).

Based on the results of this study, it can conclude that NAC 600 mg administration as an additional therapy orally 3 times a day for 3 days can influence by decreasing Gal-3 levels in IMA patients receiving fibrinolytic therapy compared to IMA patients who do not receive additional NAC therapy.

\section{Atkuri KR, Mantovani JJ, Herzenberg LA, et al. (2007). N-Acetylcysteine-a safe antidote for cysteine/glutathione defi- ciency. Curr Opin Pharmacol. 7: 355 - 3599.}

Christia P, Frangogiannis NG (2013). Targeting inflammatory pathways in myocardial Infarction. Eur J Clin Invest. 43(9): 986-995.

Dharma S, Juzar DA, Firdaus I, et al. (2012). Acute myocardial infarction system of care in the third world. Neth Heart J. 20(6): 254-259.

di Tano G, Caretta G, Maria RD, et al. (2017). Galectin-3 and outcomes after anterior-wall myocardial infarction treated by primary percutaneous coronary intervention. Biomark Med. 12(1):21-26.

di Tano G, Caretta G, Maria RD, et al. (2017). Galectin-3 predicts left ventri- cular remodelling after anterior-wall myocardial infarction treated by primary percutaneous Coronary Intervention. Heart. 103: 71-77.

Fan H, Sun B, Gu Q, et al. (2002). Oxygen radicals trigger activation of NFkappaB and AP-1 and upregulation of ICAM-1 in reperfused canine heart. Am J Physiol Heart Circ Physiol. 282: H1778-1786.

Ibanez B, James S, Agewall S, et al. (2017). ESC Guidelines for the management of acute myocardial infarction in patients presenting with ST-segment elevation: The Task Force for the management of acute myocardial infarction in patients presenting with ST-segment elevation of the European Society of Cardiology (ESC). Eur Heart J. 39:119-177.

Meijers WC, van der Velde AR, PascualFigal DA, et al. (2015). Galectin-3 and post myocardial infarction cardiac remodeling.Eur J Pharmacol. 763: 115-21.

Pasupathy S, Tavella R, Grover S, et al. (2017). Early use of N-Acetylcysteine (NAC) with nitrate therapy in patients undergoing primary percutaneous coronary intervention for ST-segment elevation myocardial infarction reduces myocardial infarct size (The NACIAM Trial). Circulation; 136(10): 894-903.

Pinkus R, Weiner LM, Daniel V (1996). Role of oxidants and antioxidants in the induction of AP-1, NF- $\kappa \mathrm{B}$, and glutathione $S$-transferase gene expression. J Biol Chem. 271: 13422 -9.

Pfeffer MA, Braunwald E (1990). Ventricular remodeling after myocardial infarction. Experimental observations and clinical implications. Circulation; 81: 1161-72. 
Indonesian Journal of Medicine (2019), 4(1): 1-8

https://doi.org/10.26911/theijmed.2019.04.01.01

Radomska DM, Skopiñski P (2012). Nacetylcysteine as an anti-oxidant and anti-inflammatory drug and its some clinical applications.Centr Eur J Immunol. 37 (1): 57-66.

Sharma UC, Mosleh W, Chaudhari MR, et al. (2016). Myocardial and Serum Galectin-3 Expression Dynamics Marks Post-Myocardial Infarction Cardiac Remodeling. Heart Lung Circ. 26(7): 736-745.

Sugiura H, Ichikawa T, Liu X, et al. (2009). $\mathrm{N}$-acetyl-L-cysteine inhibits TGFbeta1-induced profibrotic responses in fibroblasts. Pulm Pharmacol Ther. 22: 487-91.

Talasaz AH, Khalili H, Fahimi F, et al. (2011). Potential role of N-acetylcysteine in cardiovascular disorders. Therapy. 8(3): 37-245.

Talasaz AH, Khalili H, Jenab $\mathrm{Y}$, et al. (2013). N-Acetylcysteine effects on transforming growth factor- $\beta$ and tumor necrosis factor-a serum levels as pro-fibrotic and inflammatory biomarkers in patients following STsegment elevation myocardial infarction. Drugs R D. 13:199-205.

Talasaz AH, Khalili H, Fahimi F, et al. (2014). Effects of N-Acetylcysteine on the cardiac remodeling biomarkers and major adverse events following acute myocardial infarction: A randomized clinical trial. Am J Cardiovasc Drugs. 14:51-61.

van der Velde AR, Lexis CPH, Meijers WC, et al. (2016). Galectin-3 and sST2 in prediction of left ventricular ejection fraction after myocardial infarction. Clin Chim Acta. 452: 50-7.

Velagaleti RS, Pencina MJ, Murabito JM, et al. (2008). Long-term trends in the incidence of heart failure after myocardial infarction. Circulation. 118: 2057-62.

Waard MC, Velden J, Boontje NM, et al. (2009). Detrimental effect of combined exercise training and eNOS overexpression on cardiac function after myocardial infarction.Am. J. Physiol. Heart Circ. Physiol. 296(5): 15131523.

White HD, Chew DP (2008). Acute myocardial infarction. Lancet. 372(9638): 570-584.

Yang RY, Rabinovich GA, Liu FT (2008). Galectins: Structure, function and therapeutic potential. Expert Rev Mol Med. 13: e17-e39.

$\mathrm{Yu} \mathrm{L}$ (2012). The role of Galectin-3 in cardiac remodeling and fibrogenesis. Groningen. 